\title{
A European Research Council for basic research
}

To the editor:

Everyone agrees that the European Research Council (ERC) should support high-quality basic research without a concept of fair return. This would need considerable support from the scientific community. As attendees agreed at the Copenhagen meeting in October 2002, the ERC must be led and administered by scientists in much the same way as the European Molecular Biology Organisation (EMBO), the European Molecular Biology Laboratory (EMBL) and the Centrum for Nuclear Research (CERN)

O have been over the last 20 years. In fact, each of these organizations has independent international governmental and scientific delegates that control and support their activities. I propose that the heads of states in the European Union (EU), under the next chairmanship, should initiate a trial life-science ERC under the supervision of the Council of Science ministers, and that EMBO or EMBL should undertake the execution of these plans.

Neither the European Science Foundation nor the EU Commission can really fulfill these criteria, as they represent either a research council with a national loyalty, or a 20) central organization without access to scientific expertise except in an advisory role.

All these facts-as pointed out 10 years ago in a publication commemorating the restructuring of the San Raffaele Institute in Milan, Italy-make it mandatory that the prime ministers in the EU make the first decision and invest substantially in basic research through an ERC. Only a joint decision at the highest level can assure the birth of a research council that would provide the last and supporting leg of the tripod, along with applied and strategic goals in the EU Framework Programs and the developmen- tal industrial activities in Eureka. After all, the industrial breakthroughs of the last century, such as $\mathrm{X}$ rays, digital chips, lasers, antibiotics, vaccines and recombinant DNA, came from curiosity-led basic research and not from applied or strategic programs. If we are to live up to the Lisbon declaration of 2000 that Europe should be the major knowledge-based economy within a decade, all three arms of research must be established at the European level.

Once the EU leaders have made a decision, the Council of Science Ministers could be the supervisory body at the political level so that it could make a direct comparison between the framework programs and ERC activities. The investment must be on the order of $€ 3$ billion per year if it is to be comparable to national activities. This means that everyone involved-the science ministers, the EU and the national research councils-must provide a substantial contribution to initiate this activity.

The $€ 4$ billion cost for the framework programs constitutes about $2-3 \%$ of the $€ 200$ billion total budget for research and development in EU member states. Approximately $2 \%$ of the national research budgets should therefore be transferred to build up an ERC. Such a decrease in both the national and EU budgets cannot be achieved without providing fresh funds.

Let us therefore be realistic and start a fiveyear trial period with a micro-ERC dealing only with the life sciences, and select a visionary and pragmatic structure that could be expanded to all sciences when and if it turns out to be successful. A budget of around $€ 1$ billion per year is probably a minimum to determine whether Europe can organize and fund basic research at the European level.
These funds should initially be used to introduce competitive research grants initiated by scientists and to expand European graduate and postdoctoral programs. Establishing additional centers of excellence must be postponed to a later phase. To ensure that a reputable organization of life scientists in Europe is responsible for launching this enterprise, $\mathrm{EMBO}$ or perhaps its governing body, the European Molecular Biology Conference, should be approached. EMBO already has an international status and considerable experience in distributing funds for graduate and postdoctoral students. In addition, it has reviewed internationally respected research programs and supported symposia and courses for a long time. The 1,000 elected scientific members of this organization constitute a dependable backbone for high-quality peer review. EMBO should of course seek advice from other European life science organizations like the Federation of European Biochemical Societies and the European Life Scientist Organization in this process, but the executive office should be centralized. If additional centers of excellence are established, EMBL and even CERN might provide expertise.

It might, of course, constitute a conflict of interest for a retired chief executive officer of EMBL to propose such a drastic plan, but if Europe is ever to move from endless discussions to action, then allow me, after 10 years of quarantine, to introduce a pragmatic alternative.

\section{Lennart Philipson}

The author is in the Department of Cell and Molecular Biology, Medical Nobel Institute, Stockholm, Sweden, and was the director general of EMBL from 1982 to 1993.

e-mail:Lennart.Philipson@cmb.ki.se 